up in the emergency room or clinic, he had difficulty communicating with them. He literally began collecting these terms on index cards. And what began as a necessary exercise became a revealing look at a subculture that we physicians will find ourselves encountering more frequently, whether we practice medicine in big cities or small towns.

This glossary represents an important part of the physician/patient relationship: the ability to communicate. I believe a prime opportunity to identify possible chemical experiences exists during the patient's initial visit. Educating our students, interns, and housestaff to perform a comprehensive history-including a chemical history - and physical examination is most important.

We should continue to exercise this practice throughout our medical careers. Taking a thorough patient history and performing a thorough physical examination can not only uncover chemical abuse but may also help us to identify other high-risk behaviors concerning sexuality (including the potential risk for exposure to the human immunodeficiency virus) and domestic violence.

All of these sociomedical issues are difficult to discuss. Nonetheless, for us physicians to became more comfortable with the topic of chemical abuse paves the way for us to address other similarly difficult issues with our patients. This communication serves as the foundation in any physician/patient relationship. As such, I applaud Dr Cymet's contribution to the osteopathic medical literature and to patient care in general.

\footnotetext{
ANTHONY DEKKER, DO

Associate Professor

Dept of Family Medicine

Director, Adolescent and Young Adult Medicine

Chicago College of Osteopathic

Medicine

Chicago, Ill
}

\section{Plan to attend the 1992 American Academy of Osteopathy International Symposium}

We encourage all DOs, $\mathrm{PhDs}$, and students in the osteopathic medical profession to attend the international symposium, "Nociception and the Neuroendocine-Immune Connection," to be held in Cincinnati, Ohio, from June 19 through the 21, 1992. How manipulative treatment can affect the consequences of nociceptive inputs is just one of the topics of particular interest to be covered.

This meeting is the second in a series. Several years ago, the American Academy of Osteopathy decided to sponsor a series of major educational events. The purpose of these symposia is to draw together the best of the world's researchers to discuss topics of particular interest to the osteopathic medical profession. The information presented by the researchers and discussed by participants from the osteopathic medical profession is to be used to further the understanding of the clinical experience of the profession, and to generate further theory and understanding of the unique aspects of osteopathic medicine.

At the first of these symposia, held in June 1989 , ten internationally known scientists discussed their data on viscerosomatic and somatovisceral reflexes. They examined the clinical experiences and insights from the osteopathic medical profession in light of the accumulated data from the most active and renowned laboratories in the world.

This year's symposium will bring together 12 of the most renowned scientists in the field studying the effects of nociception on physiologic and psychological function, and the interrelationships between nociceptive inputs and immune function. An equal number of scientists and practitioners from the osteopathic medical profession will discuss the informa- 
tion and relate the data to osteopathic clinical experiences and theory. The symposium affords an excellent opportunity to meet some of the most eminent scientists in this field and to discuss areas of interest face to face with them.

This very important meeting should prove both exciting and stimulating for everyone, so plan to attend.

For information about the symposium, contact the American Academy of Osteopathy, PO Box 750, Newark, OH 43058-0750; (614) 3667911.

MICHAEL M. PATTERSON, PHD

Contributing Editor
Nearly $70 \%$ of the accidental medical injuries that occur in hospitals could be prevented, according to a study presented at the American Association for the Advancement of Science meeting.

Researchers retrospectively examined the hospital records of 30,195 patients. They found that $3.7 \%$ of the patients suffered an unintended or preventable injury. Preventable injuries included the prescription of the wrong drug or dosage; infections related to surgical complications; failure to diagnose disease; and technical mistakes. Unpreventable injuries were classified as unexpected allergic reactions to drugs and predictable side effects associated with necessary treatments.

The increased complexityand number - of tests, surgical procedures, and examinations partially explain the high rate of accidental medical injuries, say the researchers.

"Medical injury is indeed a hidden epidemic," commented researcher Lucian Leape, MD, of Harvard University.

When it comes to cataract surgery, older Americans have several misconceptions.

According to results from a survey published in the Feb 1 issue of Ocular Surgery News, only $18 \%$ of those surveyed (continued on page 425) 